\title{
Ipsilateral Whiskers Suppress Experience-Dependent Plasticity in the Barrel Cortex
}

\author{
Stanislaw Glazewski, ${ }^{1 *}$ Brett L. Benedetti, ${ }^{2,3 *}$ and Alison L. Barth ${ }^{2,3}$ \\ ${ }^{1}$ Institute for Science and Technology in Medicine and School of Life Sciences, Keele University, Keele, Staffordshire ST5 5BG, United Kingdom, and \\ ${ }^{2}$ Department of Biological Sciences and ${ }^{3}$ Center for the Neural Basis of Cognition, Carnegie Mellon University, Pittsburgh, Pennsylvania 15213
}

\begin{abstract}
Each cerebral hemisphere processes sensory input from both sides of the body, but the impact of this convergence on shaping and modifying receptive field properties remains controversial. Here we investigated the effect of chronic deprivation of ipsilateral sensory whiskers on receptive field plasticity in primary somatosensory cortex. In the absence of ipsilateral whiskers, cortical receptive fields were significantly larger than control after 1 week. Removal of all but a single whisker from one side of the face [single-whisker experience (SWE)] has been shown to result in the expansion of the cortical area responding to the spared whisker. We compared the effects of SWE in the presence (SWE-unilateral) and absence (SWE-bilateral) of ipsilateral whiskers. SWE-bilateral deprivation results in a significant increase in neuronal responses to spared whisker stimulation both in its cognate barrel column and in adjacent, surrounding barrel columns compared with control and SWE-unilateral deprived animals. Surround receptive fields in deprived columns were maintained in SWE-bilateral treated animals but depressed in SWE-unilateral animals. The increase in spared whisker responses was progressive with longer deprivation periods. These data show that ipsilateral whiskers can constrain receptive field size in the barrel cortex.
\end{abstract}

Key words: corpus callosum; ipsilateral; layer 2/3; plasticity; potentiation; receptive field; somatosensory cortex; vibrissa; whisker

\section{Introduction}

Integration of sensory information from the left and right sides of the body is thought to provide an animal with a seamless experience of its perceptual world. Although transection of the corpus callosum, the main anatomical structure that connects the two cortical hemispheres, results in only subtle sensory and motor deficits (Gazzaniga, 2000), many studies have confirmed that cortical neuron responses can be strongly influenced by activation of peripheral ipsilateral inputs (Armstrong-James and George, 1988; Clarey et al., 1996; Shuler et al., 2001, 2002; Pluto et al., 2005).

The clear anatomy of the rodent somatosensory cortex, where individual whiskers project to topographically defined cortical columns (Woolsey and Van der Loos, 1970), as well as the complete crossing of primary sensory afferents at the midline (Waite, 1969; Smith, 1973; Erzurumlu and Killackey, 1980), makes this an attractive system to study the influence of interhemispheric interactions in shaping receptive field properties (Clarey et al., 1996; Shuler et al., 2001, 2002; Pluto et al., 2005). In the rodent, it has been observed that deflection of ipsilateral whiskers suppresses cortical responses evoked by contralateral whisker stim-

Received July 12, 2006; accepted Feb. 20, 2007.

This work was supported by Carnegie Mellon University, the Sloan Foundation, and National Institutes of Health (NIH) Grant DA017188-02 to A.L.B.; by NIH Training Grant T32NS007433-08 to B.L.B.; and by the Wellcome Trust, Royal Society, and Physiological Society (UK) to S.G. We thank David Beil and Jesse Sheehan for expert animal care and Hyun Kim for assistance with behavioral experiments.

*S.G. and B.L.B. contributed equally to this work.

Correspondence should be addressed to Dr. Alison L. Barth, Department of Biological Sciences and Center for the Neural Basis of Cognition, Carnegie Mellon University, Pittsburgh, PA 15213. E-mail: barth@cmu.edu. DOI:10.1523/JNEUROSCI.0181-07.2007

Copyright $\odot 2007$ Society for Neuroscience $\quad$ 0270-6474/07/273910-11\$15.00/0 ulation (Shuler et al., 2001), consistent with other anatomical (Carr and Sesack, 1998) and electrophysiological (Kawaguchi, 1992) evidence supporting the conclusion that, under normal conditions, callosal inputs have a net inhibitory influence.

How does ipsilateral sensory or motor activity influence plasticity? Left and right sensory inputs may "share" behavioral use, and eliminating the contribution of one side may result in overuse of the other. In addition, corticocortical interactions may provide a direct circuit by which ipsilateral sensory information shapes neuronal response properties. These two possibilities are not mutually exclusive.

Callosal transection and suppression of ipsilateral motor activity actually improve motor performance after training (Jones and Schallert, 1994; Bury and Jones, 2002, 2004; Jones et al., 2003) and result in a use-dependent increase in dendritic arborization of pyramidal neurons in layer 5 of the contralateral motor cortex (Jones and Schallert, 1994; Bury et al., 2000b; Adkins et al., 2002). Plasticity after reducing activity from ipsilateral sensory cortex has been less well studied. In the visual cortex, monocular deprivation results in the expansion of receptive fields for callosally activated neurons at the border of area 17/18 (Watroba et al., 2001); however, at least one study indicates that plasticity may be impaired after lesion of the ipsilateral sensory cortex (Rema and Ebner, 2003).

Taking advantage of the clear anatomical and electrophysiological map of whisker inputs in mouse somatosensory cortex, we have examined the influence of chronic ipsilateral whisker deprivation on receptive field plasticity. Here we will use the terms ipsilateral and contralateral with respect to the placement of the recording electrode; for example, when recording in the left hemisphere, whiskers on the left side of the face will be referred to 
as ipsilateral. We hypothesized that if ipsilateral sensory activity has a predominantly inhibitory role in shaping the response properties of neurons, removing this inhibition might increase the capacity for spared whisker plasticity. Furthermore, the removal of ipsilateral whiskers might facilitate plasticity by encouraging increased use of the remaining spared whiskers.

A well characterized procedure for the induction of experience-dependent plasticity in barrel cortex is uni-vibrissa rearing, or single-whisker experience (SWE) (Fox, 1992; Glazewski et al., 1996; Glazewski and Fox, 1996; Barth et al., 2000; Clem and Barth, 2006). In this procedure, all but one large mystacial vibrissa are removed from one side of the rodent face. After days to weeks of treatment, spared whisker responses in layer $2 / 3$ of surrounding whisker barrel columns are potentiated. In adolescent animals, responses of layer $2 / 3$ neurons to deprived whiskers within their cognate barrel columns are depressed, and the contrast between evoked activity from spared and deprived whiskers is enhanced (Glazewski and Fox, 1996). The cellular and molecular mechanisms that underlie experience-dependent plasticity are of great interest, and it has been hypothesized that an imbalance of activity between the spared, active whisker and its silent, inactive neighbors drives this change in firing rates after whisker stimulation (Feldman and Brecht, 2005). If sensory-evoked activity from ipsilateral whiskers normally reduces receptive field size and inhibits neuronal responses, then the absence of this activity might facilitate the consolidation of expanded spared whisker receptive fields by providing a wide cortical substrate that can be activated by whisker deflection.

We found that removal of ipsilateral sensory input is a strong activator of plasticity, resulting in the significant enhancement of both spared and deprived surround whisker responses. This result was observed when all contralateral whiskers were intact (no competition) as well as when only a single contralateral whisker remained (strong competition). Although this plasticity may be related in part to increased use of spared whiskers, these data suggest a model in which neuronal activity evoked via ipsilateral whiskers can constrain plasticity and may have important implications for stimulating functional recovery in sensory systems after brain injury or stroke in humans (Taub et al., 2002).

\section{Materials and Methods}

Animals. Recordings were made from 839 neurons of 41 wild-type male C57BL/6 mice aged 35-45 d at the start of deprivation. All experiments were compliant with the United Kingdom 1986 Animals (Scientific Procedures) Act or were performed with the approval of the Carnegie Mellon Institutional Animal Care and Use Committee.

Nomenclature. Ipsilateral and contralateral whiskers are identified with respect to the placement of the recording electrode; for example, when recording in the left hemisphere, whiskers on the left side of the face are referred to as ipsilateral. All recordings were performed in the same hemisphere.

Deprivation. Four experimental deprivation paradigms were used in this study (see Fig. 1). For each, whiskers were removed at the start of and every second day of the deprivation period by application of steady tension to the whisker base. Whisker removal was performed under isoflurane anesthesia. Deprivations lasted for $7 \mathrm{~d}$ unless indicated otherwise. This deprivation technique does not affect vibrissa innervation ( $\mathrm{Li}$ et al., 1995) and has been described in detail previously (Glazewski et al., 1998). In deprived animals, contralateral whiskers were allowed to regrow for 7-9 d. In no cases were ipsilateral whiskers permitted to regrow.

Anesthesia and surgery. Animals were anesthetized with urethane (1.5 $\mathrm{g} / \mathrm{kg}$ of body weight) with trace amounts of acepromazine, injected intraperitoneally. All recordings were done at anesthetic level stage III-3 level, during which a hindlimb pinch withdrawal reflex and corneal blink reflex are present and $\delta$ waves occur at between 1 and $2 \mathrm{~Hz}$ with occa- sional spindle waves (Fox and Armstrong-James, 1986). Supplemental doses of urethane (10\% of initial) were administered to maintain anesthesia depth. Body temperature was monitored and maintained at $37^{\circ} \mathrm{C}$ with a rectal thermometer and heating blanket (Harvard Apparatus, Holliston, MA). For recording, the skull was thinned over the barrel cortex with a dental drill $(0-3 \mathrm{~mm}$ caudal from bregma and $2-4 \mathrm{~mm}$ lateral to midline). A small hole was made in the skull before each electrode penetration with a 30 gauge hypodermic needle tip. The skull and exposed cortex were kept moist by superfusion of $0.1 \mathrm{~m}$ phosphate buffer.

Electrodes and recording. Homemade single-barreled glass-insulated carbon fiber microelectrodes were used to record extracellular potentials from the cortex (Armstrong-James et al., 1980). Electrodes were lowered perpendicular to the cortical surface. Electrode penetrations were made in the barrel columns representing the spared whisker and immediately surrounding barrel columns. Action potentials from single units were isolated with a window discriminator, recorded with the Neurolog system (Digitimer, Welwyn Garden City, Hertfordshire, UK), and filtered between 0.1 and $700 \mathrm{~Hz}$ with a $50 \mathrm{~Hz}$ notch filter. The signals were amplified $2000 \times$. Neurons in layers $2-4(0-450 \mu \mathrm{m})$ were sampled at 50 $\mu \mathrm{m}$ intervals.

Stimulus. Stimulation consisted of a $10 \mathrm{~ms}, 1^{\circ}$ vertical deflection of a single contralateral whisker delivered at $1 \mathrm{~Hz}$ ( 50 stimuli applied per each whisker tried) by means of a fast piezoelectric bimorph wafer attached to a lightweight glass capillary driven from a voltage source (DS-2; Digitimer). A voltage source (Digitimer) was triggered with Spike2 software [Cambridge Electronic Design (CED), Cambridge, UK]. Ipsilateral whiskers were never stimulated during recording. Because the animals were anesthetized, there was no whisking behavior during the recording session.

Histology. A small lesion ( $1 \mu \mathrm{A}$, direct current; $10 \mathrm{~s}$; tip negative) was made in layer 4 to mark the location of each electrode penetration. After each experiment, animals were deeply anesthetized and perfused through the heart with $0.1 \mathrm{M}$ PBS followed by a buffered solution of $4.0 \%$ paraformaldehyde. The brain was removed, and the cortex was flattened as described previously (Strominger and Woolsey, 1987) and left overnight in $20 \%$ sucrose in a buffered solution of $4.0 \%$ paraformaldehyde. Sections of $40 \mu \mathrm{m}$ thickness were cut tangentially to the surface of flattened cortex with a freezing microtome, and the tissue was reacted for cytochrome oxidase (Wong-Riley, 1979). Stained sections were later digitally analyzed for lesion location and post hoc correction of recording depths (i.e., laminar location). Cells $<300 \mu \mathrm{m}$ below the pial surface were classified as layer 2/3, and cells from 301 to $450 \mu \mathrm{m}$ were classified as layer 4 .

Analysis. The magnitude of responses measured in spikes per stimulus $(\mathrm{s} / \mathrm{s})$ and their latencies were calculated with Spike2 software (CED). Spontaneous activity of cells was collected in a $50 \mathrm{~ms}$ time window immediately before the stimulus. Evoked activity was collected from 3 to 53 $\mathrm{ms}$ after stimulus and corrected by subtraction of firing rates from spontaneous activity. The data analysis was done after ensuring that the vertical and horizontal distributions of cells recorded in the vicinity of the intact whisker representation were equivalent among deprivation groups. Responses to stimulation of principal, spared, and surround vibrissas were averaged among cells pooled from each treatment group. Whisker dominance histograms were calculated as described previously (Glazewski and Fox, 1996). Datasets failed the Shapiro-Wilkes test for normal distributions, so nonparametric statistics were used for all comparisons. The Kruskal-Wallace test (a nonparametric ANOVA) was used for multiple comparisons of more than two datasets. The Mann-Whitney test (a nonparametric $t$ test) was used for direct pairwise comparisons of two datasets.

Behavioral analysis. Nine animals were used for passive observation of stereotyped behaviors within the home cage. Animals ( $n=3$ SWE-unilateral; $n=3$ SWE-unilateral; $n=3$ sham-plucked controls) were observed $30 \mathrm{~min}, 24 \mathrm{~h}$, or $7 \mathrm{~d}$ after plucking. "Grooming” was defined as instances when an animal repeatedly ran its forepaws across the length of the snout. "Rearing" was defined as instances during which an animal stood on its hindlimbs and supported itself against the side of the cage with its forelimbs, often accompanied by active whisking against the cage surface. "Burrowing" was defined as instances during which the animal fully submerged its snout and head in the cage bedding chips. Observa- 
tional sessions lasted for 10 min each, during which one of the above behaviors was tracked.

Nine additional animals were tested for performance on the visual "cliff" assay (three per group: control, SWE-unilateral, and SWEbilateral) (Schiffman et al., 1970). Animals were tested $30 \mathrm{~min}, 24 \mathrm{~h}$, and $7 \mathrm{~d}$ after plucking. The visual cliff apparatus consisted of a clear Plexiglas box supported on one side by a table surface such that in one-fourth of the box, high-contrast paper was visible beneath it. The other end of the box was supported such that three-fourths of the box surface appeared as a visual cliff. Animals were placed on the "ground" side of the box and monitored for the following parameters: attempts at crossing past the cliff; time to first cliff crossing; side of each cliff crossing (i.e., whiskerintact or whisker-deprived side); and total time spent either on the ground or over the apparent cliff. Observation sessions lasted $5 \mathrm{~min}$.

\section{Results}

\section{Chronic absence of ipsilateral whiskers potentiates} sensory-evoked responses

Initially, animals were deprived of all ipsilateral whiskers for a period of $7 \mathrm{~d}$ (Figs. $1 \mathrm{~B}, 2 \mathrm{~B}$ ). After this time, animals were prepared for single-unit recording in barrel cortex, and well isolated responses of neurons from layer $2 / 3$ and layer 4 to stimulation of individual facial whiskers were assessed.

In layer 2/3, both principal whisker (e.g., stimulation of the D2 whisker while recording in the D2 barrel column) and surround whisker (e.g., stimulation of the D3 whisker while recording in the D2 barrel column) responses were significantly elevated compared with control (principal whisker responses: control, $1.75 \pm$ 0.09 vs all-ipsilateral deprived, $2.11 \pm 0.10 \mathrm{~s} / \mathrm{s} ; p<0.05$; surround whisker responses: control, $0.47 \pm 0.03$ vs all-ipsilateral deprived, $0.68 \pm 0.03 \mathrm{~s} / \mathrm{s} ; p<0.001$ ) (Fig. 2C,D).

Whisker dominance histograms compare principal and surround responses from the same cell, a calculation that cancels out potential differences between experiments attributable to variability in surgical preparation or anesthesia level. For this reason, whisker dominance histograms can be highly informative about relative changes in surround and principal whisker responses. The increase in surround whisker responses as well as the average evoked responses were observed in the whisker dominance histogram (Fig. 2E,F).

Increased responsivity in layer $2 / 3$ could be driven by increased activity in layer 4 ; however, in this preparation, as in many others (Fox, 1992), layer 4 neuronal responses were not significantly different from control (principle whisker responses: control, $2.85 \pm 0.23$ vs all-ipsilateral deprived, $2.49 \pm 0.21 \mathrm{~s} / \mathrm{s}$; $p=0.16$; data not shown).

Although these data show that both surround and principal whisker responses were increased, we found that surround whisker responses were disproportionately affected by this manipulation. The cumulative distribution of whisker dominance values showed a shift toward higher surround whisker responses (Fig. $2 \mathrm{~F}$ ), and surround responses showed a 1.44-fold increase over control values compared with only a 1.21 -fold increase in principal whisker responses versus control.

\section{Ipsilateral sensory input and spared whisker plasticity}

Ipsilateral sensory inputs may normally reduce contralaterally driven activity in the cortex and sharpen response properties by reducing surround receptive fields of cortical neurons (Shuler et al., 2001; Pluto et al., 2005; Schmidt et al., 2006). Our data indicate that the cumulative effect of reduced ipsilateral sensory activity is an increase in stimulus-driven activity in the sensoryspared hemisphere. We next examined whether this effect would facilitate other types of experience-dependent plasticity, such as that induced by SWE.

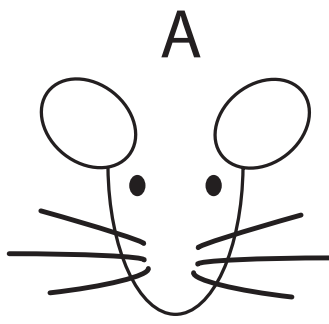

control

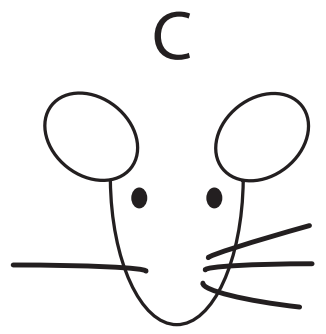

SWE - unilateral

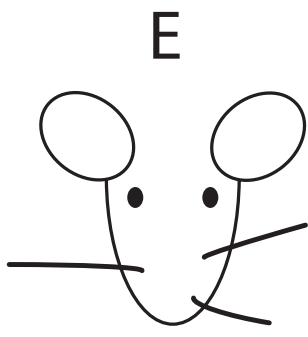

D1-most

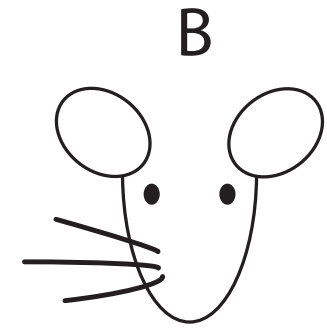

all-ipsi dep

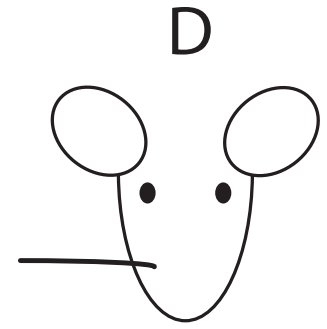

SWE - bilateral
Figure 1. Schematic of experimental conditions. $\boldsymbol{A}$, Control animals with all whiskers intact. $\boldsymbol{B}$, Animals with all ipsilateral whiskers deprived (all-ipsi dep) for 7d. C, SWE-unilateral deprivation, in which all of the large facial vibrissas on one side of the snout except for the D1 whisker on the same side were removed for $7 \mathrm{~d}$, followed by a 7-9 d period of regrowth of the contralateral whiskers. $\boldsymbol{D}$, SWE-bilateral deprivation, in which of the larger facial vibrissas on both sides of the animal's snout except for the contralateral D1 whisker were removed for $7 \mathrm{~d}$, followed by a 7-9 d period of regrowth of the contralateral whiskers. $\boldsymbol{E}$, D1-most deprivation, similar to SWE-unilateral, except that in addition to removing all the large contralateral vibrissas except $\mathrm{D} 1$, the ipsilateral C1, C2, D1, D2, E1, $\delta$, and $\gamma$ vibrissas were also removed (indicated by an X in the barrel map to the right) for $7 \mathrm{~d}$ followed by $7-9 \mathrm{~d}$ period of regrowth.

Animals were subjected to SWE as described in Materials and Methods (SWE-unilateral or SWE-bilateral) for $7 \mathrm{~d}$, followed by a short (7-9 d) period of whisker regrowth of only the spared whisker side (Fig. $3 A, B$ ). SWE-bilateral deprivation was remarkably effective at increasing responses to stimulation of the spared, D1 whisker in adjacent barrel columns, showing significantly more firing after D1 whisker deflection compared with SWE-unilateral deprivation (Fig. 3C). Seven days of SWE-unilateral deprivation induced a significant potentiation of spared whisker responses compared with control (control surround responses, $0.47 \pm 0.03$ vs SWE-unilateral surround D1 responses, $1.02 \pm 0.07 \mathrm{~s} / \mathrm{s} ; p<0.001$ ) (but see Glazewski and Fox, 1996); however, we found that 7d of SWEbilateral was successful at inducing an even greater increase in D1 responses in layer $2 / 3$ neurons of neighboring columns ( $1.29 \pm 0.10 \mathrm{~s} / \mathrm{s} ; p<0.05$; vs SWE-unilateral; $p<0.001$; vs control) (Fig. 3C). The difference between SWE-unilateral and SWE-bilateral was also apparent in the whisker 

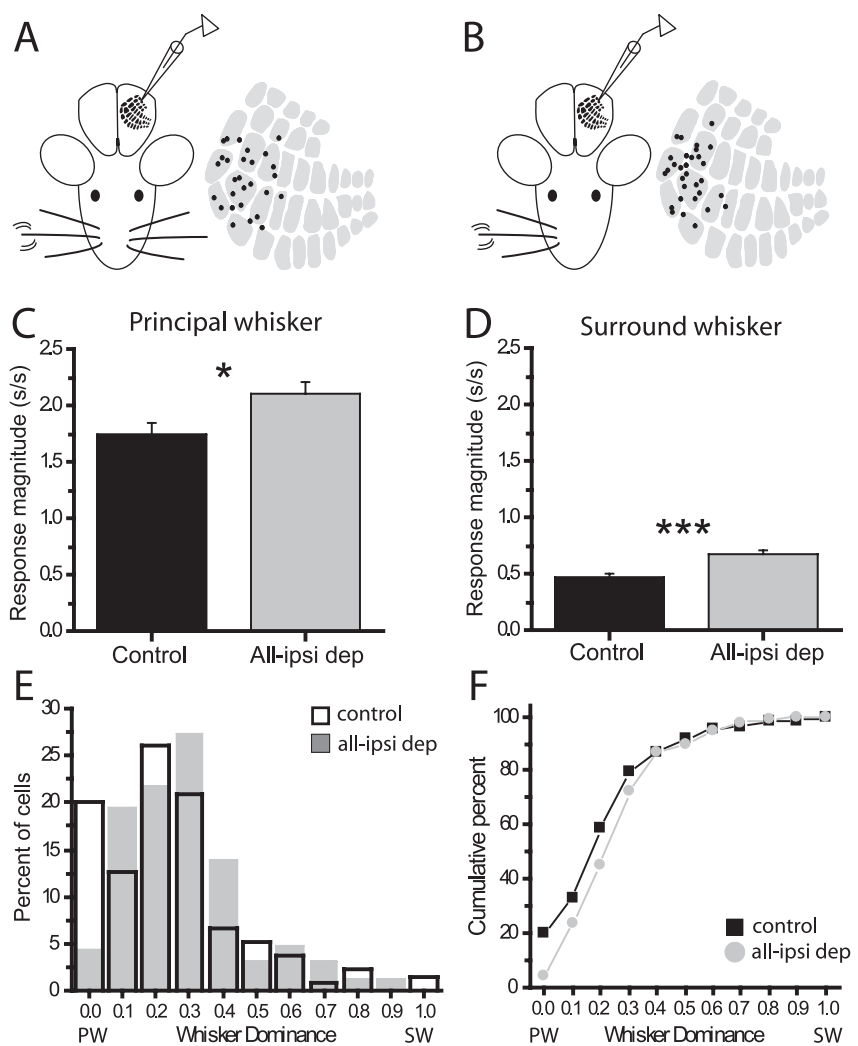

Figure 2. Chronic absence of ipsilateral sensory inputs increases receptive field size. $\boldsymbol{A}, \boldsymbol{B}$, Left, Summary of deprivation and recording conditions for control ( $A, 6$ animals) and allipsilateral deprived ( $\boldsymbol{B}, 9$ animals) mice. After $7 \mathrm{~d}$ of deprivation, animals were prepared for in vivo single-unit recordings performed in barrel cortex ipsilateral to the deprived whiskers. Right, Schematics of the layer 4 barrel map indicating the position of each recording electrode. C, Mean ( \pm SEM) layer $2 / 3$ neuronal responses (spikes per stimulus) to deflection of the principal whisker (e.g., D2 stimulation recorded in the D2 barrel) for cells from control ( $n=135$ cells) and all-ipsilateral deprived ( $n=165$ cells) animals. $\boldsymbol{D}$, Mean ( \pm SEM) surround whisker responses (e.g., D3 stimulation recorded in the D2 barrel) for the same cells as in C. $\boldsymbol{E}$, Comparison of whisker dominance for individual cells from control and all-ipsilateral deprived animals. $\boldsymbol{F}$, Cumulative distribution of cells as in $\boldsymbol{D}$ for control (black squares) and all-ipsilateral deprived (gray circles) animals. Statistical comparison between control and all-ipsilateral deprived animals; ${ }^{*} p<0.05 ;{ }^{* * *} p<0.001$. All-ipsi dep, All-ipsilateral deprived; PW, principal whisker; $\mathrm{SW}$, surround whisker.

dominance indexes (Fig. 3E) $(p<0.05)$. Response magnitude differences between these two experimental conditions were highlighted when cells were segregated by whisker dominance. Even cells that were still dominated by the principal whisker showed significant potentiation of spared whisker response after SWE-bilateral deprivation, a finding that was not observed after SWE-unilateral deprivation (Fig. $3 F$ ). No changes in response to stimulation of the spared whisker were observed in layer 4 neurons from the surrounding barrel columns under either condition (control, $0.53 \pm 0.11$; SWE-unilateral, $0.56 \pm$ 0.12; SWE-bilateral, $0.58 \pm 11 \mathrm{~s} / \mathrm{s} ; p=0.27$ ).

\section{Ipsilateral sensory deprivation and depression of principal whisker responses}

Both SWE deprivations result in the depression of deprived principal whisker responses (Fig. $4 C, D$ ), possibly because of a longterm depression-like mechanism that occurs in vivo (Allen et al., 2003). SWE deprivations result in an apparent redistribution of responses away from the principal whisker in favor of responses to the spared whisker (Fig. 3E). This imbalance might reflect an increased depression of deprived, principal whisker responses, an
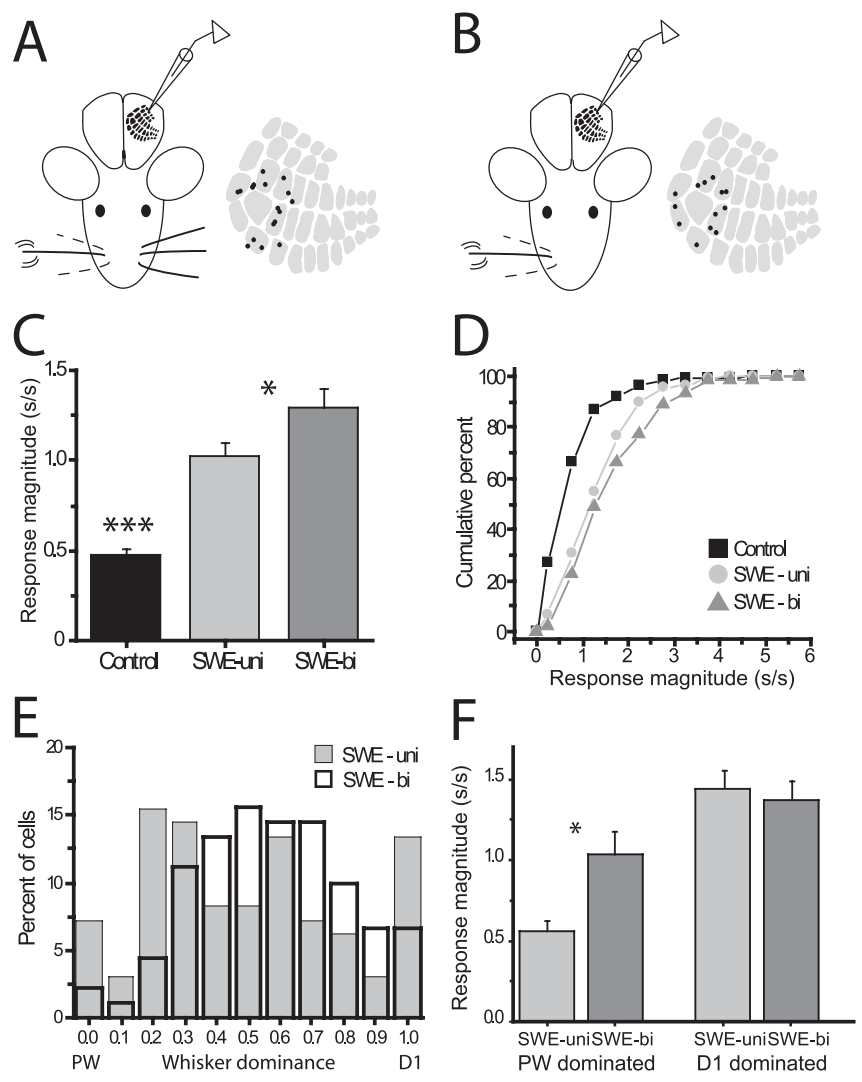

Figure 3. Spared whisker potentiation in deprived barrel columns is enhanced in the absence of ipsilateral whisker inputs. $\boldsymbol{A}, \boldsymbol{B}$, Left, Deprivation and recording configurations for the SWE-unilateral ( $\boldsymbol{A}, 7$ animals) and SWE-bilateral ( $\boldsymbol{B}, 5$ animals) conditions, indicating stimulation of the spared D1 whisker (solid lines). Animals were deprived for $7 \mathrm{~d}$, followed by 7-9 $\mathrm{d}$ of whisker regrowth (dashed lines) and then prepared for in vivo single-unit recording. Right, Schematics of the layer 4 barrel map showing the locations of recording electrodes in deprived barrels surrounding the D1 barrel. C, Mean ( \pm SEM) layer 2/3 neuronal response to stimulation of the spared D1 whisker for cells from SWE-unilateral $(n=112)$ and SWE-bilateral $(n=90)$ animals compared with control surround whisker responses $(n=135)$. ${ }^{* * *} p<0.001$, comparing control with either SWE-unilateral or SWE-bilateral; ${ }^{*} p<0.05$, comparing SWEunilateral with SWE-bilateral. $\boldsymbol{D}$, Cumulative distribution of D1 responses binned according to response magnitude for SWE-unilateral (circles) and SWE-bilateral (triangles) compared with control SWE responses (squares). $\boldsymbol{E}$, Comparison of whisker dominance for individual cells from SWE-unilateral (gray bars) and SWE-bilateral (black outlined bars) animals. $\boldsymbol{F}$, Mean ( \pm SEM) response to D1 stimulation for cells from SWE-unilateral and SWE-bilateral animals separated by their whisker dominance; PW-dominated cells correspond to those with WVDI values between 0 and 0.49 and D1-dominated cells correspond to those with WVDI values between 0.5 and 1.0. ${ }^{*} p<0.05$ comparing SWE-unilateral with SWE-bilateral. SWE-uni, SWE-unilateral; SWE-bi, SWE-bilateral; PW, principal whisker; WVDI, weighted vibrissae dominance index.

increased potentiation of spared whisker responses, or both; however, we found that the magnitude of principal whisker responses for cells that are dominated by their principal whisker (i.e., stimulating D2 and recording in D2) remains the same for SWE-unilateral and SWE-bilateral conditions (data not shown). In contrast, cells that became dominated by the spared input showed depression of principal whisker responses under both deprivation conditions (data not shown).

Interestingly, surround whisker responses in previously deprived barrel columns (e.g., response to stimulation of whisker D3 recording in the D2 barrel column) were less depressed after SWE-bilateral treatment (control, $0.47 \pm 0.03$ vs SWE-bilateral, $0.40 \pm 0.04 \mathrm{~s} / \mathrm{s} ; p=0.03$ ), and were stronger compared with SWE-unilateral surround responses $[0.25 \pm 0.03 \mathrm{~s} / \mathrm{s} ; p<0.001 \mathrm{vs}$ control (Fig. 4E, F); SWE-unilateral vs SWE-bilateral; $p<0.001$ ]. 

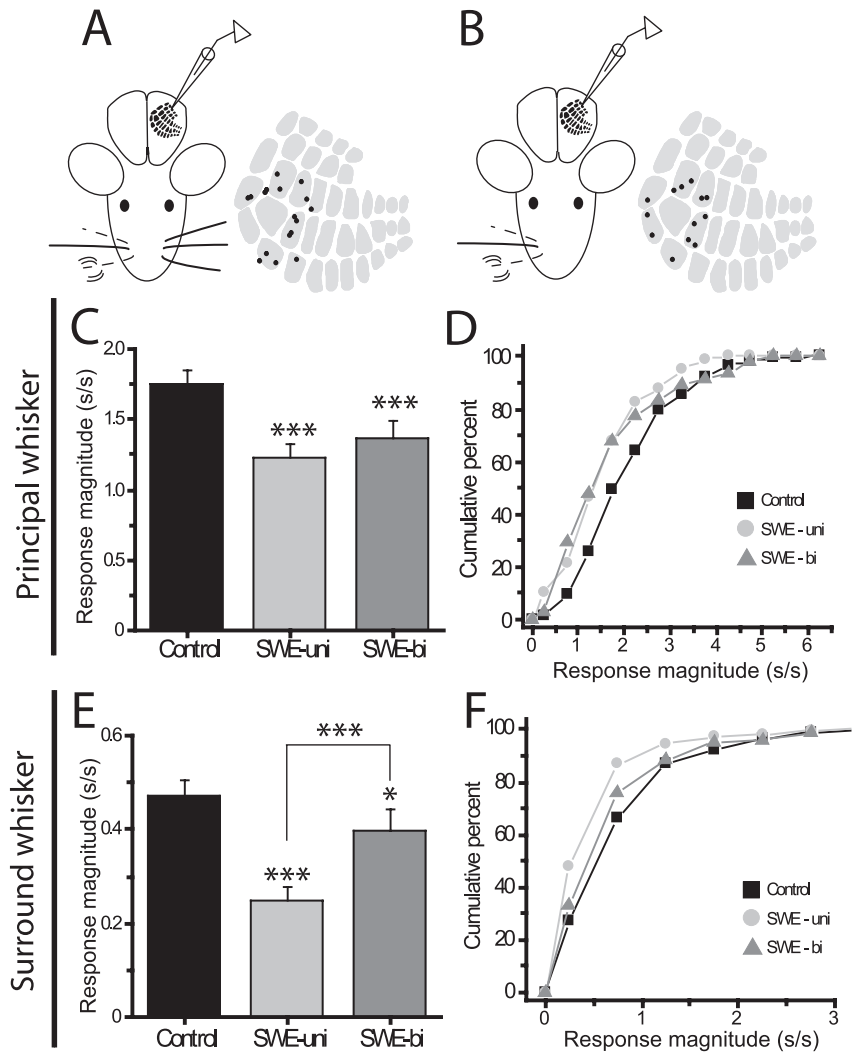

Figure 4. Surround whisker depression in deprived barrel columns is reduced in the absence of ipsilateral whisker inputs. $A, B$, Left, Deprivation and recording configurations for the SWEunilateral ( $\boldsymbol{A}, 7$ animals) and SWE-bilateral ( $\boldsymbol{B}, 5$ animals) conditions, indicating stimulation of the deprived, regrown whiskers (dashed lines). Right, Schematics of the layer 4 barrel map showing the locations of recording electrodes in deprived barrels surrounding the D1 barrel. C, Mean ( \pm SEM) layer $2 / 3$ neuronal response to stimulation of the deprived, regrown principal whiskers (e.g., D2 stimulation recorded in the D2 barrel) for cells from SWE-unilateral $(n=99)$ and SWE-bilateral $(n=96)$ animals compared with control surround whisker responses $(n=$ 135). ${ }^{* * *} p<0.001$ comparing either SWE-unilateral or SWE-bilateral with control. D, Cumulative distribution of deprived principal whisker responses binned according to response magnitude for SWE-unilateral (circles) and SWE-bilateral (triangles) compared with control (squares). $\boldsymbol{E}$, Mean ( \pm SEM) layer 2/3 neuronal response to stimulation of the deprived, regrown surround whiskers (e.g., D3 stimulation recorded in the D2 barrel) for cells from SWEunilateral $(n=99)$ and SWE-bilateral $(n=96)$ animals compared with control surround whisker responses $(n=135)$. For comparisons, ${ }^{*} p<0.05$; ${ }^{* * *} p<0.001$. $\boldsymbol{F}$, Cumulative distribution of deprived surround whisker responses binned according to response magnitude for SWE-unilateral (circles) and SWE-bilateral (triangles) compared with control (squares). SWE-uni, SWE-unilateral; SWE-bi, SWE-bilateral.

\section{Potentiation of spared whisker responses in the spared barrel column}

Does the absence of ipsilateral sensory input result in potentiation of D1 responses within the D1 barrel column? Although the experimental precedent for this is scant, previous analyses have revealed a slight but significant shift in spiking or synaptic responses in layer $2 / 3$ neurons within the spared barrel column after short (18-24 h) periods of SWE (Barth et al., 2000; Clem and Barth, 2006). This, combined with the enhanced plasticity of spared whisker response in the surrounding barrel columns after SWE-bilateral, suggested that we might find increased responses in the spared barrel column itself in the absence of ipsilateral sensory-evoked activity.

We found that SWE-bilateral is not only extremely effective at driving spared whisker plasticity within surrounding barrel columns, but that it is also highly effective at increasing spared whisker responses within the spared barrel itself. Seven days of SWE-
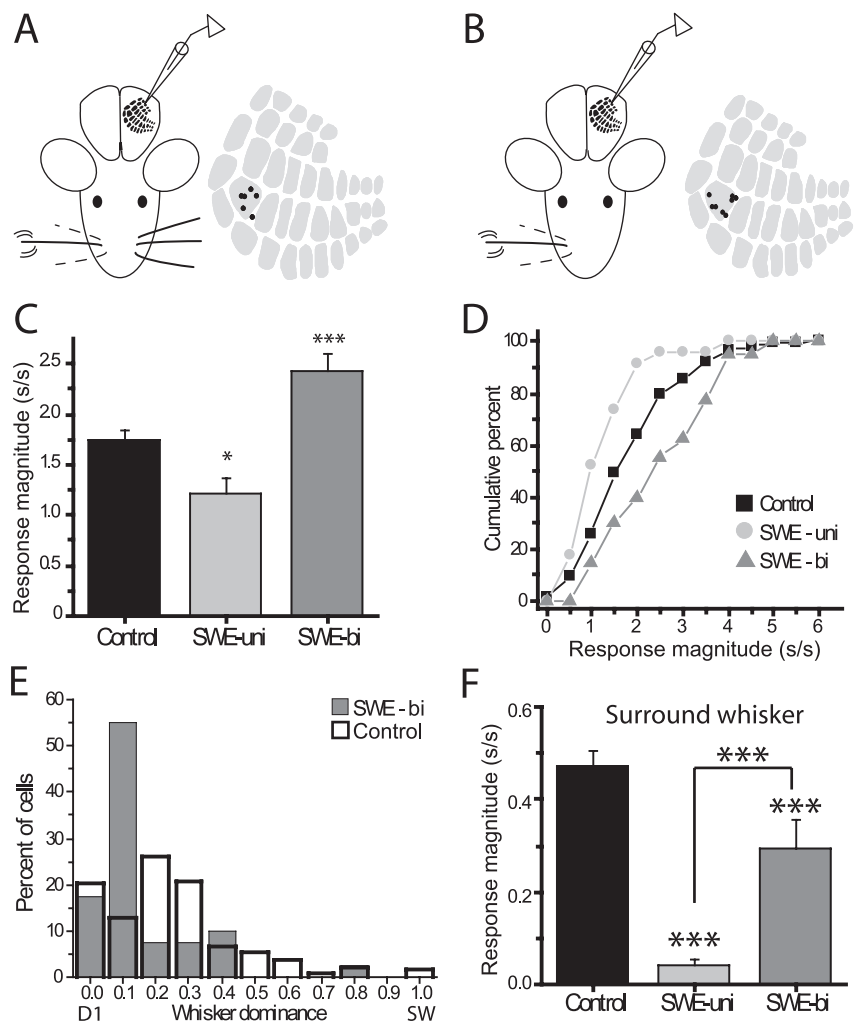

$\mathrm{F}$

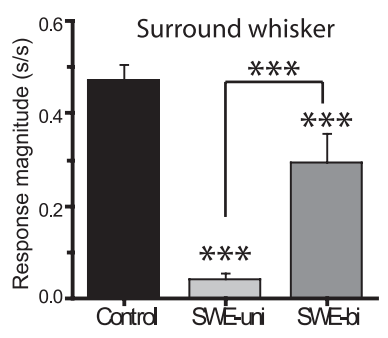

Figure 5. Rapid potentiation of spared whisker responses in the spared barrel column after SWE-bilateral. $\boldsymbol{A}, \boldsymbol{B}$, Left, Deprivation and recording configurations for SWE-unilateral $(\boldsymbol{A})$ and SWE-bilateral $(\boldsymbol{B})$ animals, indicating stimulation of the spared D1 whisker (solid lines). Right, Schematics of the layer 4 barrel map showing the locations of recording electrodes in the spared D1 barrel. C, Mean ( \pm SEM) layer 2/3 neuronal response to stimulation of the spared D1 whisker for cells from SWE-unilateral $(n=23)$ and SWE-bilateral $(n=40)$ animals compared with control principal whisker responses $(n=135)$. For comparisons with control, ${ }^{*} p<0.05$; ${ }^{* * *} p<0.001$. D, Cumulative distribution of spared D1 whisker responses binned according to response magnitude for SWE-unilateral (circles) and SWE-bilateral (triangles) compared with control (squares). $\boldsymbol{E}$, Comparison of whisker dominance for individual cells from SWE-bilateral recorded in the spared barrel (gray bars) and control (black outlined bars). $\boldsymbol{F}$, Mean ( \pm SEM) layer 2/3 neuronal response to stimulation of surround whiskers for cells recorded in the spared D1 barrel from SWE-unilateral and SWE-bilateral animals compared with control surround whisker responses. ${ }^{* * *} p<0.001$. SWE-uni, SWE-unilateral; SWE-bi, SWE-bilateral; SW, surround whisker.

unilateral treatment resulted in the significant depression of spared whisker responses within the spared barrel column (SWEunilateral, $1.21 \pm 0.15$ vs control, $1.75 \pm 0.09 \mathrm{~s} / \mathrm{s} ; p=0.014$ ); however, SWE-bilateral induces a significant potentiation of spared whisker responses within the spared barrel column $(2.42 \pm 0.18 \mathrm{~s} / \mathrm{s} ; p<0.001$; vs control) (Fig. $5 C)$. The change in sensory-evoked activity is specific to the SWE-bilateral manipulation, observed by comparing the cumulative distribution histogram of spike output, during which cells from SWEbilateral animals show a significant shift to cells with higher response rates (Fig. 5D). Whisker dominance histograms that compare spared and surround whisker responses for individual cells from the spared barrel column indicate a pronounced shift in the histogram to neurons with strong responses to D1 stimulation (Fig. 5E).

SWE-unilateral animals show a profound, significant depression of surround responses $(0.04 \pm 0.01 \mathrm{~s} / \mathrm{s} ; p<0.001$; vs control) (Fig. 5F). This depression is reduced after SWE-bilateral treatment, during which surround whisker responses are closer to control levels (SWE-bilateral, $0.30 \pm 0.06$ vs control, $0.47 \pm$ $0.03 \mathrm{~s} / \mathrm{s} ; p<0.001)$. 


\section{Increased plasticity is progressive over time}

Previous reports of experience-dependent plasticity in the barrel cortex have traditionally used longer periods of SWE deprivation than those described here (Fox, 1992; Glazewski and Fox, 1996; Glazewski et al., 1996). To determine whether the enhanced plasticity observed after $7 \mathrm{~d}$ of SWE-bilateral is enhanced by longer deprivation periods, we performed SWE-unilateral and SWEbilateral deprivations for $18 \mathrm{~d}$ and then assayed layer $2 / 3$ neuronal responses as described above (Fig. 6). These experiments also served to show whether the effects that we observed after $7 \mathrm{~d}$ of deprivation were the results of acute disinhibition of spared whisker responses or whether they might also involve the accumulation of experience-dependent changes in response properties.

In agreement with previous reports (Glazewski and Fox, 1996), 18 d of SWE-unilateral were sufficient to induce an increased representation of the spared input in neighboring deprived barrel columns (SWE-unilateral, $0.87 \pm 0.08$ vs control, $0.47 \pm 0.03 \mathrm{~s} / \mathrm{s} ; p<0.001$ ) (Fig. 6C); however, as was the case with the shorter, $7 \mathrm{~d}$ deprivations, $18 \mathrm{~d}$ SWE-bilateral produced an even greater potentiation of the spared input compared with $18 \mathrm{~d}$ SWE-unilateral (SWE-bilateral, $1.72 \pm 0.17 ; p<0.001$; vs SWEunilateral or control) (Fig. 6C). Whisker dominance indexes showed a significantly larger shift toward spared whisker responses for $18 \mathrm{~d}$ SWE-bilateral cells than $18 \mathrm{~d}$ SWE-unilateral cells $(p<0.001)$ (Fig. 6G,H). We found that the increased spared whisker potentiation observed in SWE-bilateral animals accumulates over time, with respect to both response magnitude (7 vs $18 \mathrm{~d}$ SWE-bilateral; $p<0.01$ ) (Fig. $6 E$ ) and whisker dominance $(p<0.05)$. In contrast, spared whisker potentiation and whisker dominance induced by the SWE-unilateral deprivation showed no further increase during this interval ( 7 vs $18 \mathrm{~d}$ spared whisker potentiation: $p=0.33$; whisker dominance: $p=0.9$ ).

We also analyzed responses to spared whisker stimulation recorded from cells within the spared barrel column (Fig. 6D). Here, layer $2 / 3$ cells again showed a modest but not significant increase in responses relative to $7 \mathrm{~d}$ of deprivation for both conditions (SWE-bilateral, 18 vs $7 \mathrm{~d}: p=0.86$; SWE-unilateral, 7 vs $18 \mathrm{~d}: p=0.20)$.

\section{Behavioral changes are not pronounced}

One potential explanation for the increase in plasticity with the SWE-bilateral deprivation procedure might be that animals with only a single remaining whisker simply use this whisker more than they would when they retain a full complement of whiskers on the ipsilateral side. If plasticity is use dependent, then increased use of the single remaining whisker might provoke potentiation of spared whisker responses in the absence of any potential corticocortical interaction. We investigated behavior that might impact whisker stimulation in animals subjected to SWE-unilateral and SWE-bilateral deprivations and observed no significant differences in burrowing, grooming, or rearing (when the animals are actively whisking) behaviors at either $24 \mathrm{~h}$ or $7 \mathrm{~d}$ after deprivation between these two groups ( $n=3$ per group).

We further examined the behavior of animals within these two groups in a visual cliff test, an assay that is robustly whisker dependent in rats (Schiffman et al., 1970). We also observed no significant differences in time-to-cross or number of crossings of the apparent visual cliff for either group, nor in whether the animals used the single whisker side or the intact-deprived side to test the floor before crossing ( $n=3$ per group). In fact, animals with all large facial whiskers deprived on both sides still crossed the apparent cliff, indicating a potential difference between mice and rats in this assay. Although there was a trend for the SWE-
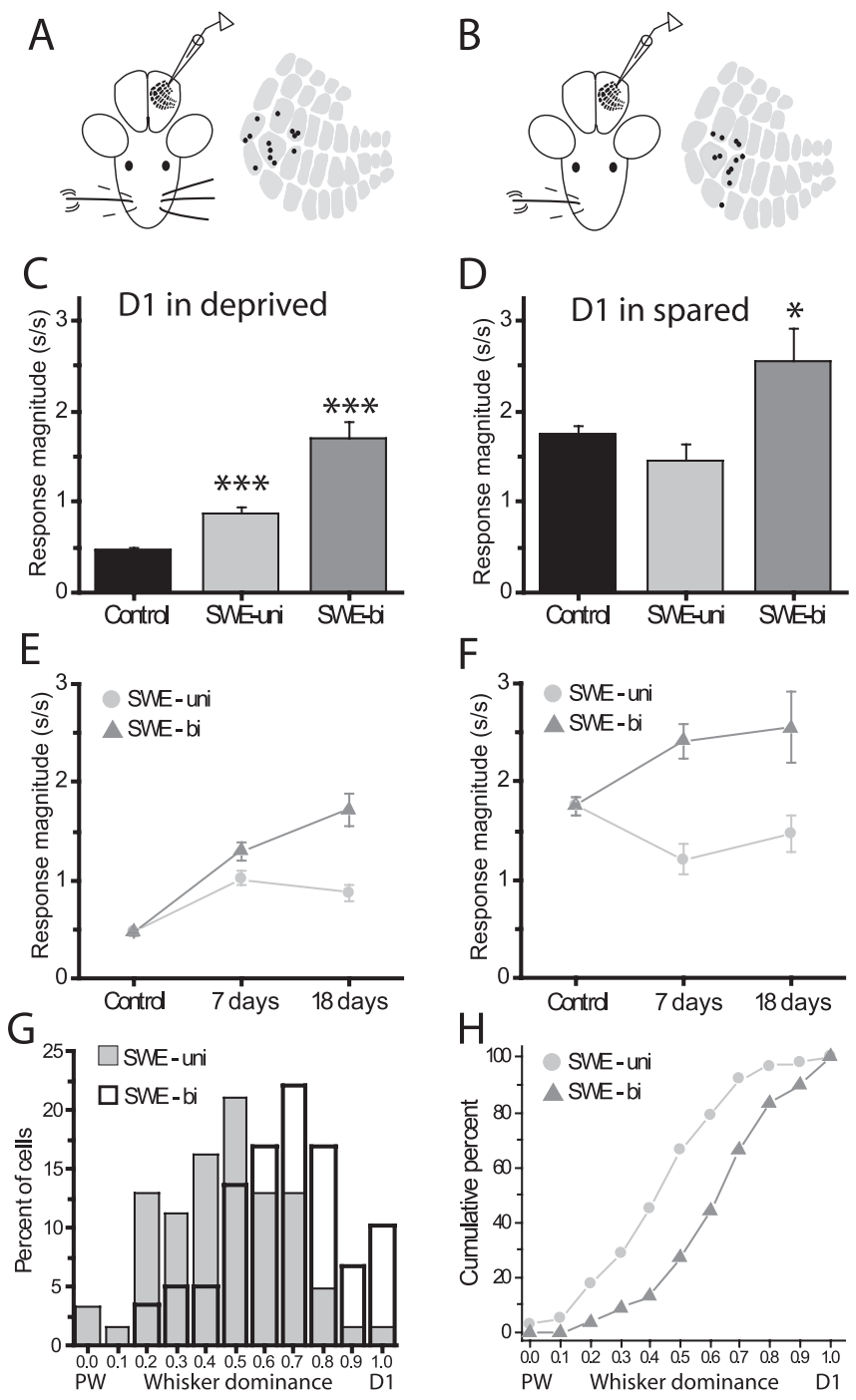

Figure 6. Spared whisker potentiation is progressive over time in the absence of ipsilateral whisker inputs. $\boldsymbol{A}, \boldsymbol{B}$, Left, Summary of deprivation and recording conditions for $18 \mathrm{~d}$ SWEunilateral ( $n=3$ animals) and $18 \mathrm{~d}$ SWE-bilateral ( $n=4$ animals) mice, indicating stimulation of the spared D1 whisker (solid line). Right, Schematics of the layer 4 barrel map indicating the position of recording electrodes. C, Mean ( \pm SEM) layer $2 / 3$ neuronal response recorded in deprived barrels for cells from SWE-unilateral $(n=62)$ and SWE-bilateral $(n=59)$ animals compared with control surround whisker responses $(n=135) .{ }^{* * *} p<0.001$ comparing either SWE-unilateral or SWE-bilateral with control. $\boldsymbol{D}$, Mean ( \pm SEM) layer $2 / 3$ neuronal response recorded in the spared barrel for cells from SWE-unilateral $(n=22)$ and SWE-bilateral $(n=14)$ animals compared with control principal whisker responses $(n=135)$. ${ }^{*} p<0.05$ compared with control. $\boldsymbol{E}$, Time course of spared whisker potentiation in deprived barrels from 7 to $18 \mathrm{~d}$ for SWE-unilateral (circles) and SWE-bilateral (triangles) compared with control surround whisker values. $\boldsymbol{F}$, Time course of spared whisker responses in the spared barrel from 7 to $18 \mathrm{~d}$ for SWE-unilateral (circles) and SWE-bilateral (triangles) compared with control principal whisker values. G, Comparison of whisker dominance for individual cells from SWE-unilateral (gray bars) and SWE-bilateral (black outlined bars) animals. $\boldsymbol{H}$, Cumulative distribution of whisker dominance for cells from SWE-unilateral (circles) and SWE-bilateral (triangles) mice. SWE-uni, SWEunilateral; SWD-bi, SWE-bilateral; PW, principal whisker.

bilateral animals used the single spared whisker slightly more than the SWE-unilateral animals (a side-use bias of 1.6 for SWEbilateral vs 1.3 for SWE-unilateral animals, in which a ratio of 1 indicates equal use of both sides in crossing the visual cliff), this difference was not significant. It is possible that future experiments using a more sophisticated analysis (such as high-speed video in a roughness detection task) with a larger sample size 
might be sensitive enough to reveal changes in whisker use between these two experimental conditions.

\section{Partial removal of ipsilateral whiskers} facilitates plasticity

Although other investigators have used silencing or lesion of one hemisphere to examine the contribution of that hemisphere in shaping response properties to contralateral whisker stimulation, these approaches result in behavioral neglect of the peripheral whiskers corresponding to the lesioned hemisphere (Rema and Ebner, 2003; Li et al., 2005) and do not provide a clear way to distinguish between overuse and interhemispheric influences. Instead, we designed a new whisker deprivation paradigm that combined SWE with removal of some ipsilateral whiskers while retaining most of those whiskers (Fig. 1E, D1-most). Animals in this group had all whiskers except the D1 whisker on the contralateral whisker pad removed for $7 \mathrm{~d}$. The D1, D2, C1, C2, E1, $\gamma$, and $\delta$ whiskers were also removed from the ipsilateral whisker pad. Because these animals retain most of their ipsilateral whiskers, they should not feel the necessity to overuse the single spared (D1) whisker; however, a potential interhemispheric influence of these absent whiskers on plasticity might be observed. Because inhibition from ipsilateral whiskers is roughly homotopic (White and DeAmicis, 1977; Olavarria et al., 1984; Koralek et al., 1990) (but see Welker et al., 1988), removal of a handful of ipsilateral whiskers should result in a situation similar to the SWE-bilateral deprivation without the confounding factor of a behavioral overuse of the spared D1 whisker.

Consistent with this expectation, the D1-most manipulation yielded stronger spared whisker responses in the spared column (Fig. 7C) compared with the normal depression of spared whisker responses observed after SWE-unilateral (D1-most, $1.6 \pm$ $0.16 \mathrm{~s} / \mathrm{s} ; p<0.05$; vs SWE-unilateral). Although we did not observe an increase in spared whisker responses within deprived columns compared with SWE-unilateral (D1-most, $0.97 \pm 0.08$ vs SWE-unilateral, $1.02 \pm 0.07 \mathrm{~s} / \mathrm{s} ; p=0.34$; vs control, $0.47 \pm$ $0.03 \mathrm{~s} / \mathrm{s} ; p<0.001$ ), deprived surround whisker responses in the D1-most condition were elevated compared with SWE-unilateral values (D1-most, $0.31 \pm 0.03$ vs SWE-unilateral, $0.25 \pm 0.03 \mathrm{~s} / \mathrm{s}$; $p<0.05)$. Because the D1-most deprivation represents a condition during which we expect minimal behavioral overuse compared with SWE-unilateral, we conclude that the difference between SWE-unilateral and D1-most spared whisker responses in the spared barrel column is based on interhemispheric interactions.

\section{Spontaneous activity is enhanced in the spared column after SWE-bilateral}

Our results are consistent with other studies showing that ipsilateral sensory activity has a net inhibitory effect (Shuler et al., 2001; Pluto et al., 2005; Schmidt et al., 2006) and that reduced inhibition may facilitate increased responsivity of contralateral whiskers. One measure of whether SWE-bilateral deprivation results in a net decrease of tonic inhibition is the analysis of spontaneous firing activity. Because ipsilateral whiskers are not manipulated during the course of recording even in control animals, we expected that differences in spontaneous activity would not be
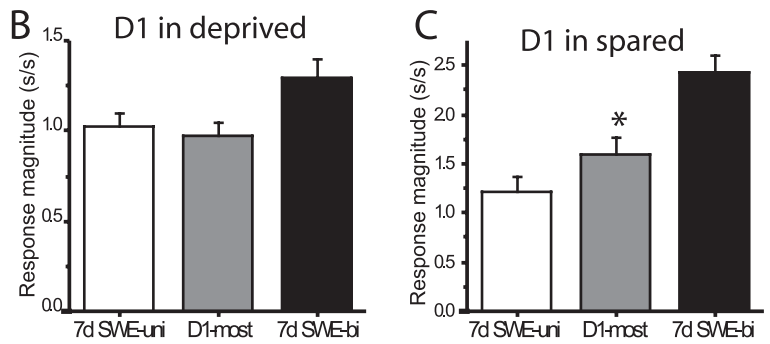

7dShE-uni D1 most 7d SWE-bi

Figure 7. Partial removal of ipsilateral whisker inputs facilitates spared whisker plasticity. $\boldsymbol{A}$, Left, Deprivation and recording

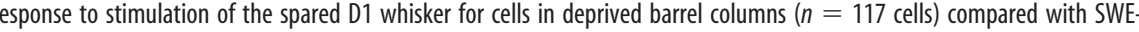
compared with SWE-unilateral and SWE-bilateral deprivations. ${ }^{*} p<0.05$ for comparisons with either SWE-unilateral or SWEbilateral. SWE-uni, SWE-unilateral; SWE-bi, SWE-bilateral.
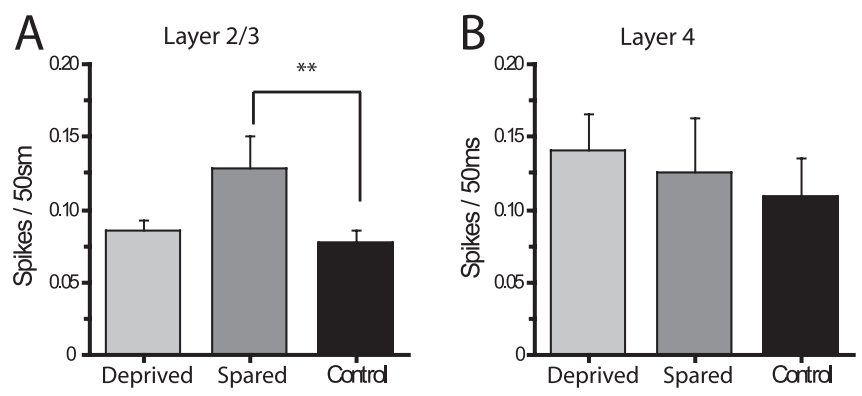

Figure 8. Spontaneous activity is increased in the spared barrel column of SWE-bilateral animals. $\boldsymbol{A}$, Mean ( \pm SEM) layer 2/3 neuronal spontaneous activity for cells from SWE-bilateral animals shown separately for deprived ( $n=96$ cells) and spared ( $n=40$ cells) barrels compared with controls ( $n=140$ cells). $\boldsymbol{B}$, Mean ( \pm SEM) layer 4 neuronal spontaneous activity for cells from SWE-bilateral animals shown separately for deprived ( $n=25$ cells) and spared ( $n=$ 11 cells) barrels compared with controls ( $n=30$ cells). ${ }^{* *} p<0.01$.

caused by acute sensory-evoked inhibition. Rather, increased levels of spontaneous firing might be an indicator of circuit-level modifications that permit enhanced transfer of excitatory activity.

To address this issue, we examined firing rates between whisker stimulation trials of isolated neurons in control animals compared with those from SWE-bilateral deprived animals. Spontaneous firing activity was analyzed and averaged according to the laminar and column location (Fig. 8). Layer 2/3 neurons in whisker-deprived barrel columns showed firing rates similar to those from control animals (SWE-bilateral deprived, $0.09 \pm 0.01$ vs control, $0.08 \pm 0.1$ spikes per $50 \mathrm{~ms} ; p>0.5$ ). Spontaneous activity was significantly elevated in layer $2 / 3$ of the spared barrel in SWE-bilateral deprived animals compared with control (SWEbilateral spared barrel, $0.13 \pm 0.02 \mathrm{~s} / \mathrm{s} ; p<0.01)$. In layer 4 , spontaneous activity was similar between control and SWEbilateral deprived animals (control, $0.11 \pm 0.03$ vs SWE-bilateral spared barrel, $0.13 \pm 0.04$ vs SWE-bilateral deprived barrel, $0.14 \pm 0.03$ spikes per $50 \mathrm{~ms} ; p>0.2$ ).

\section{Discussion}

Our results show that chronic deprivation of ipsilateral whiskers enhances potentiation of active sensory inputs. This is true when all contralateral whiskers are intact (all-ipsilateral deprived) as well as when there is an imbalance in sensory input caused by the removal of all but one whisker from the contralateral whisker pad (SWE-bilateral and D1-most). 


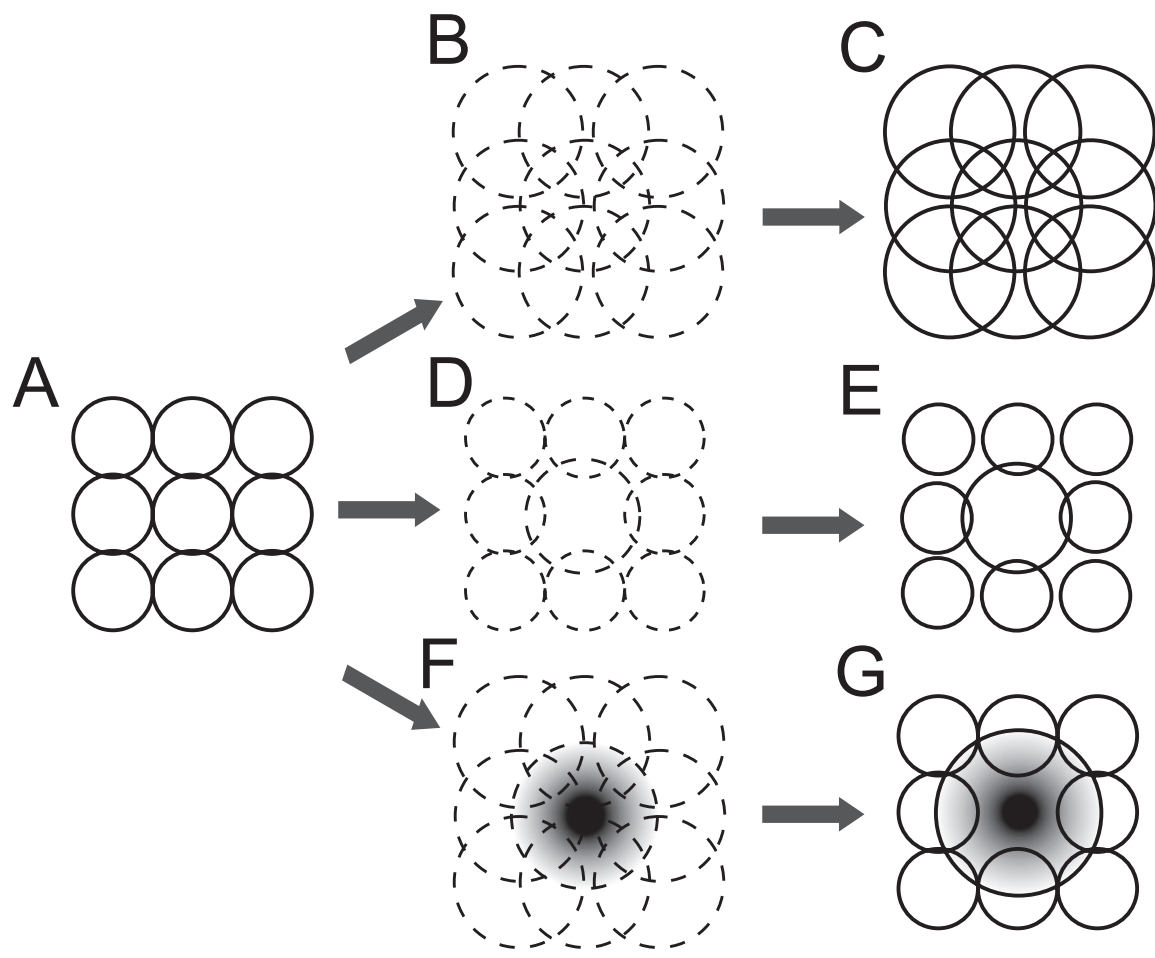

Figure 9. Model for the influence of ipsilateral sensory activity on receptive field size and neuronal response magnitude. $\boldsymbol{A}$, Simplified schematic of control receptive fields, showing limited overlap between whiskers. $\boldsymbol{B}$, After deprivation of all ipsilateral whiskers, all receptive fields expand because of reduced inhibition of principal and surround whisker responses. $C$, These changes are consolidated by experience so that receptive fields are stably enlarged compared with control. $\boldsymbol{D}$, After SWE-unilateral deprivation, spared whisker responses spread into surrounding barrels, and this effect is consolidated by experience in $\boldsymbol{E}$. Deprived whisker receptive fields are smaller in $\boldsymbol{E}$ to reflect the depression of principal whisker responses after SWE-unilateral deprivation. $\boldsymbol{F}$, SWE-bilateral deprivation results in the expansion of both spared and deprived whisker receptive fields caused by reduced inhibition of principal and surround whisker responses. Spared whisker responses are preferentially consolidated by experience, resulting in the larger expansion of spared whisker receptive fields. $\mathbf{G}$, Reduced inhibition of spared whisker responses promotes potentiation of spared whisker responses within the spared barrel column, indicated by the dark spot in the center circle.

The experiments presented here represent a detailed investigation into how neuronal responses to stimulation of intact sensory inputs can be altered by the removal of ipsilateral whiskers. First, during SWE-bilateral, spared whisker responses are potentiated in the spared barrel column as well as in surrounding deprived barrel columns. In comparison, spared whisker responses are actually reduced in the spared barrel column after SWEunilateral, and the potentiation in deprived columns is more modest. Second, surround whisker responses in deprived columns are preserved after SWE-bilateral, whereas they are strongly depressed in SWE-unilateral. Third, the increase in potentiation after SWE-bilateral is progressive over longer deprivation periods, particularly for spared whisker responses in deprived cortex. Our finding that SWE-unilateral and SWEbilateral treated animals are behaviorally similar, plus results from the D1-most deprivation protocol showing increased spared whisker responses in the spared column compared with SWE-unilateral, are consistent with a role of interhemispheric interactions in modulating plasticity in this brain area. In addition, our results indicate that ipsilateral whiskers can reduce surround whisker responses in contralateral cortex and thus may serve to sharpen receptive field properties in the normal behaving animal.

\section{Behavioral overuse versus callosal influences}

The absence of ipsilateral sensory inputs may profoundly influence use of the spared whiskers such that animals with only one spared whisker (SWE-bilateral) may use this whisker much more than under SWEunilateral conditions. For instance, it has been shown that whisker use may depend on the number of whiskers present: removal of all but a single whisker leads to increased use of that remaining whisker in a gap-crossing task (Celikel and Sakmann, 2007). It is far from clear, however, that increased whisker use would result in potentiated whisker responses. For example, Polley et al. (1999) showed that the cortical area activated by whisker deflection actually shrinks after exposure to a sensoryrich environment in which animals are encouraged to use the whiskers. Second, passive whisker overstimulation of a single whisker leads to reduced 2-deoxyglucose uptake in the corresponding barrel columns (Welker et al., 1992).

Increased use of the spared whisker is unlikely to explain all of the results presented here for several additional reasons. First, we found that surround receptive field responses for deprived whiskers (i.e., D3 responses recording in the D2 barrel column, where both D2 and D3 are deprived) after SWE-bilateral were significantly increased compared with SWEunilateral. Because both the D2 and D3 whiskers were removed during the deprivation period, it is difficult to ascribe this result to overuse of these whiskers. Second, by using the D1-most deprivation treatment, where only a few whiskers were removed from the ipsilateral side, spared whisker responses were significantly larger in the spared column compared with SWE-unilateral. Because this treatment is unlikely to result in whisker overuse, a reasonable alternative explanation is a change in callosally mediated activity from the (mostly) whisker-intact hemisphere. We note that this manipulation did not result in enhanced spared whisker potentiation in deprived barrels. The reason for this is unclear and will require further experiments to examine the behavioral and interhemispheric contributions to this effect.

\section{Influence of ipsilateral whiskers on receptive field properties}

How might ipsilateral sensory input affect receptive field size via callosally mediated activity? On the basis of the results presented here, we have developed a simplified model that may help explain the existing data and direct and constrain future experiments.

In control animals, whisker receptive fields are relatively small, and strong responses to whisker stimulation are found mainly in the barrel column corresponding to that whisker (Fig. $9 A$ ). In the absence of inhibition driven by ipsilateral sensory activity, receptive fields expand, and both principal and surround whisker responses increase (Fig. 9B), an effect that is consolidated by experience and reflected in an increase in apparent receptive field size in all-ipsilateral deprived animals (Fig. 9C). When there is an imbalance in sensory activity, driven by removal of all but one whisker from the contralateral hemisphere, the spared whisker normally shows an activity-dependent expansion of its receptive field into the surrounding barrel columns. During SWE- 
unilateral deprivation, inhibition from ipsilateral whiskers reduces total levels of activity and thus reduces the receptive field expansion that can occur (Fig. 9D,E). When inhibition from ipsilateral whiskers is removed during SWE-bilateral deprivation, sensory-evoked activity in the contralateral hemisphere is increased, providing a stronger driving force for plastic changes to occur (Fig. 9F). Experience-dependent consolidation of this increased activity is manifest as increased spared whisker responses both in the spared barrel column and in neighboring barrel columns (Fig. 9G). This model is also consistent with previous experimental data (Clarey et al., 1996; Shuler et al., 2001; Watroba et al., 2001; Pluto et al., 2005).

Anatomical substrates for the influence of ipsilateral whiskers These data are consistent with a model by which evoked sensory activity from ipsilateral whiskers broadly inhibits activity in the contralateral cortex. We propose that interhemispheric connections through the corpus callosum are a likely source of this input.

Although callosal afferents themselves are glutamatergic (Carr and Sesack, 1998), much evidence supports the conclusions that they have a net inhibitory effect, reducing evoked whisker responses and apparent receptive field size. For example, cooling of the ipsilateral hemisphere in the digit representation of macaques (cortical area 3b) (Clarey et al., 1996) causes an immediate expansion of contralateral receptive fields, shown with single-unit recordings. This is also true in visual cortex, where neurons activated through the corpus callosum show expanded receptive fields after several weeks of monocular deprivation (Watroba et al., 2001). Moreover, in barrel cortex, stimulation of ipsilateral whiskers immediately before contralateral whiskers results in a decreased response of cortical neurons compared with stimulation of contralateral whiskers alone (Shuler et al., 2001). Finally, stimulation of the corpus callosum in slice elicits an initial EPSC followed by a sustained IPSC, observed during whole-cell recording, suggesting that callosal afferents can powerfully engage inhibitory circuits (Kawaguchi, 1992). Despite these findings, other studies have shown that activity from the opposite hemisphere increases or has no effect on sensory responses in the recorded hemisphere (Armstrong-James and George, 1988; Kossut et al., 1988; Rema and Ebner, 2003; Li et al., 2005); thus, there remains significant controversy in this field.

Callosal projections in somatosensory cortex are thought to be roughly homotopic (White and DeAmicis, 1977; Olavarria et al., 1984; Koralek et al., 1990), although other studies have indicated that there are few direct connections between barrel fields (Armstrong-James and George, 1988) and that callosal projections from the barrel field can be highly distributed over many different contralateral cortical areas, including S2 and M1 (Welker et al., 1988). Importantly, because all afferents cross the midline after the trigeminal nucleus in the brainstem (Killackey, 1973; Pidoux and Verley, 1979), the source of all ipsilateral sensory information must proceed, directly or indirectly, via the corpus callosum. In general, supragranular layers have a subset of neurons that project to contralateral supragranular cortex, and infragranular neurons (particularly layer 5b) project to contralateral infragranular cortex; this is also true in the somatosensory cortex of rodents (Pidoux and Verley, 1979). Consistent with our hypothesis that the effect described here may be related to the intracortical transfer of sensory information, barrels within layer 4 receive almost no callosal innervation (Olavarria et al., 1984) and display no change in response properties after ipsilateral sensory deprivation (data not shown).

\section{Enhanced potentiation of spared whisker responses}

Removal of ipsilateral whiskers increased responses to contralateral whisker stimulation under various experimental circumstances. First, removal of all ipsilateral whiskers (all-ipsilateral deprived) significantly increased both principal and surround whisker responses. Second, removal of all ipsilateral whiskers was remarkably effective at facilitating spared whisker plasticity, most significantly through enhancing spared whisker responses. After SWE-bilateral, the potentiation of spared whisker responses was observed not only in adjacent, previously deprived barrel columns, but also within the spared barrel column itself, where a profound increase in spikes per stimulus of the spared whisker was found. Previous investigations have shown that although 2-3 weeks of SWE-unilateral deprivation are required to drive potentiation of spared whisker responses in adjacent barrel columns in rats, this treatment is relatively ineffective at enhancing spared whisker responses within the spared barrel column itself (Glazewski and Fox, 1996; Glazewski et al., 1996). This effect has not been observed previously with the SWE paradigm under even long-term modification of sensory input and represents the most robust example of sensory-induced potentiation that has been described to date in the juvenile or adult barrel cortex.

It is interesting to note that increased spikes/stimulus in response to spared whisker stimulation can occur independently within the spared barrel column and in deprived barrel columns, i.e., potentiation does not have to spread from the spared column into deprived areas. For example, SWE-unilateral shows potentiated spared whisker responses in deprived columns with both 7 and $18 \mathrm{~d}$ of treatment without an increase in responses within the spared column itself (Fig. 6E,F). However, we always observed an increase in spared whisker responses in adjacent deprived columns when there was potentiation in the spared column itself. In these and previous experiments (Glazewski and Fox, 1996), potentiation of spared whisker responses has been observed in adjacent deprived columns without a corresponding potentiation within the spared column, suggesting that the increase in spared whisker responses does not necessarily emanate from the spared column itself. These results suggest that there may be several mechanisms that underlie the experience-dependent changes in response properties seen here.

\section{Surround whisker responses}

An important hypothesis that has arisen in this field is that callosal inputs play an important role in suppressing abnormal, confusing inputs (Pluto et al., 2005; Woolsey, 2005). Our data showing that the removal of ipsilateral whiskers has a stronger effect on increasing surround whisker compared with principal whisker responses is consistent with this view. In both all-ipsilateral deprived and SWE-bilateral deprived animals, spared whisker surround responses were enhanced significantly more than spared whisker principal responses, suggesting that ipsilateral sensory input may have a greater effect on surround rather than principal whisker responses. Indeed, surround responses in deprived barrel columns were less depressed in all-ipsilateral, SWE-bilateral, and D1-most than in SWE-unilateral deprived animals. This might be accomplished by ipsilateral sensory input differentially activating cross-barrel inhibition or because of a fundamental difference in the plasticity of within- and between-column excitatory and inhibitory connections.

\section{Evoked and spontaneous activity}

Our results indicate that the chronic deprivation of ipsilateral whiskers during SWE-bilateral deprivation can alter both spon- 
taneous and evoked sensory activity in layer $2 / 3$ of the spared barrel column. It is likely that these two observations are related and that the change in spontaneous activity reflects a strengthening of the underlying cortical circuitry in layer $2 / 3$ that was driven by the absence of ipsilateral sensory input during the deprivation period. The cellular and synaptic substrates that result in an increase in spontaneous activity within layer $2 / 3$ may be related to those responsible for the increase in spared whisker responses within this layer as well.

Although SWE-bilateral deprivation was highly effective at driving changes in response properties in layer $2 / 3$, it did not alter responses within layer 4 , consistent with this layer being aplastic in juvenile and adult animals (Fox, 1992; Diamond et al., 1994; Glazewski and Fox, 1996). Because we did not observe a significant increase in activity within layer 4 , the anatomical and synaptic substrates that underlie the increase in spontaneous activity most likely are restricted to layer $2 / 3$. For example, more efficient transmission between layer 4 and layer $2 / 3$, increased connectivity between layer $2 / 3$ excitatory neurons, or reduced inhibition within layer $2 / 3$ circuits might facilitate signal amplification and increased firing rates of these cells.

\section{Comparison with previous studies}

Some previous investigations have found that ablation or pharmacological silencing of the ipsilateral cortex results in reduced spontaneous and evoked activity and can compromise plasticity (Rema and Ebner, 2003; Li et al., 2005). It is likely that these manipulations induce a multitude of effects attributable to retrograde neuronal degeneration (Bury et al., 2000a) as well as eliminate both spontaneous and evoked activity from the directly affected barrel cortex. By eliminating only evoked sensory activity, this study is more constrained than previous investigations. Indeed, differences between these results and ablation or silencing studies may illuminate specific roles for spontaneous and evoked activity in the processing of tactile stimuli.

A second difference between those studies and this one is the species used. Rats and mice have a surprisingly different organization of the barrel field: mice show essentially no septal neurons in layer 4, in contrast to rats (Welker and Woolsey, 1974). Multiwhisker inputs from the medial posterior nucleus of the thalamus, which synapse onto septal layer 4 neurons in rats (Chmielowska et al., 1989), are directed to superficial layer $2 / 3$ via layer 5 a inputs in mice (Bureau et al., 2006). Because of the role of septal neurons in providing surround whisker responses, it is conceivable that this anatomical difference may partly explain the discrepancy in results. Although we have not resolved the longstanding debate about the role of callosal activity in shaping response properties, it is possible that subtle differences in experimental manipulation and the species used underlie the difference in results that we observed.

\section{Conclusion}

The data presented here show that the absence of ipsilateral whiskers can profoundly influence response properties of neurons within primary somatosensory cortex. The enhanced plasticity that is induced by SWE-bilateral deprivation may be available to provoke experience-dependent changes in brain function elsewhere in the CNS, and we hope that this manipulation may be useful for experimentally teasing apart the cellular and synaptic substrates that underlie this effect. In addition, these results suggest that the reduction of ipsilateral sensory activity may facilitate recovery of sensory function after unilateral injury or stroke, just as this technique has been used to recover motor function (Taub et al., 2002).

\section{References}

Adkins DL, Bury SD, Jones TA (2002) Laminar-dependent dendritic spine alterations in the motor cortex of adult rats following callosal transection and forced forelimb use. Neurobiol Learn Mem 78:35-52.

Allen CB, Celikel T, Feldman DE (2003) Long-term depression induced by sensory deprivation during cortical map plasticity in vivo. Nat Neurosci 6:291-299.

Armstrong-James M, George MJ (1988) Bilateral receptive fields of cells in rat Sml cortex. Exp Brain Res 70:155-165.

Armstrong-James M, Fox K, Millar J (1980) A method for etching the tips of carbon fiber microelectrodes. J Neurosci Methods 2:431-432.

Barth AL, McKenna M, Glazewski S, Hill P, Impey S, Storm D, Fox K (2000) Upregulation of cAMP response element-mediated gene expression during experience-dependent plasticity in adult neocortex. J Neurosci 20:4206-4216.

Bureau I, von Saint Paul F, Svoboda K (2006) Interdigitated paralemniscal and lemniscal pathways in the mouse barrel cortex. PLoS Biol 4:e382.

Bury SD, Jones TA (2002) Unilateral sensorimotor cortex lesions in adult rats facilitate motor skill learning with the "unaffected" forelimb and training-induced dendritic structural plasticity in the motor cortex. J Neurosci 22:8597-8606.

Bury SD, Jones TA (2004) Facilitation of motor skill learning by callosal denervation or forced forelimb use in adult rats. Behav Brain Res 150:43-53.

Bury SD, Eichhorn AC, Kotzer CM, Jones TA (2000a) Reactive astrocytic responses to denervation in the motor cortex of adult rats are sensitive to manipulations of behavioral experience. Neuropharmacology 39:743-755.

Bury SD, Adkins DL, Ishida JT, Kotzer CM, Eichhorn AC, Jones TA (2000b) Denervation facilitates neuronal growth in the motor cortex of rats in the presence of behavioral demand. Neurosci Lett 287:85-88.

Carr DB, Sesack SR (1998) Callosal terminals in the rat prefrontal cortex: synaptic targets and association with GABA-immunoreactive structures. Synapse 29:193-205.

Celikel T, Sakmann B (2007) Sensory integration across space and in time for decision making in the somatosensory system of rodents. Proc Natl Acad Sci USA 104:1395-1400.

Chmielowska J, Carvell GE, Simons DJ (1989) Spatial organization of thalamocortical and corticothalamic projection systems in the rat SmI barrel cortex. J Comp Neurol 285:325-338.

Clarey JC, Tweedale R, Calford MB (1996) Interhemispheric modulation of somatosensory receptive fields: evidence for plasticity in primary somatosensory cortex. Cereb Cortex 6:196-206.

Clem RL, Barth A (2006) Pathway-specific trafficking of native AMPARs by in vivo experience. Neuron 49:663-670.

Diamond ME, Huang W, Ebner FF (1994) Laminar comparison of somatosensory cortical plasticity. Science 265:1885-1888.

Erzurumlu RS, Killackey HP (1980) Diencephalic projections of the subnucleus interpolaris of the brainstem trigeminal complex in the rat. Neuroscience 5:1891-1901.

Feldman DE, Brecht M (2005) Map plasticity in somatosensory cortex. Science 310:810-815.

Fox K (1992) A critical period for experience-dependent synaptic plasticity in rat barrel cortex. J Neurosci 12:1826-1838.

Fox K, Armstrong-James M (1986) The role of the anterior intralaminar nuclei and $\mathrm{N}$-methyl-D-aspartate receptors in the generation of spontaneous bursts in rat neocortical neurones. Exp Brain Res 63:505-518.

Gazzaniga MS (2000) Cerebral specialization and interhemispheric communication: does the corpus callosum enable the human condition? Brain 123:1293-1326.

Glazewski S, Fox K (1996) Time course of experience-dependent synaptic potentiation and depression in barrel cortex of adolescent rats. J Neurophysiol 75:1714-1729.

Glazewski S, Chen CM, Silva A, Fox K (1996) Requirement for alphaCaMKII in experience-dependent plasticity of the barrel cortex. Science 272:421-423.

Glazewski S, McKenna M, Jacquin M, Fox K (1998) Experience-dependent depression of vibrissae responses in adolescent rat barrel cortex. Eur J Neurosci 10:2107-2116. 
Jones TA, Schallert T (1994) Use-dependent growth of pyramidal neurons after neocortical damage. J Neurosci 14:2140-2152.

Jones TA, Bury SD, Adkins-Muir DL, Luke LM, Allred RP, Sakata JT (2003) Importance of behavioral manipulations and measures in rat models of brain damage and brain repair. ILAR J 44:144-152.

Kawaguchi Y (1992) Receptor subtypes involved in callosally-induced postsynaptic potentials in rat frontal agranular cortex in vitro. Exp Brain Res 88:33-40.

Killackey HP (1973) Anatomical evidence for cortical subdivisions based on vertically discrete thalamic projections from the ventral posterior nucleus to cortical barrels in the rat. Brain Res 51:326-331.

Koralek KA, Olavarria J, Killackey HP (1990) Areal and laminar organization of corticocortical projections in the rat somatosensory cortex. J Comp Neurol 299:133-150.

Kossut M, Hand PJ, Greenberg J, Hand CL (1988) Single vibrissal cortical column in SI cortex of rat and its alterations in neonatal and adult vibrissa-deafferented animals: a quantitative 2DG study. J Neurophysiol 60:829-852.

Li L, Rema V, Ebner FF (2005) Chronic suppression of activity in barrel field cortex downregulates sensory responses in contralateral barrel field cortex. J Neurophysiol 94:3342-3356.

Li X, Glazewski S, Lin X, Elde R, Fox K (1995) Effect of vibrissae deprivation on follicle innervation, neuropeptide synthesis in the trigeminal ganglion, and S1 barrel cortex plasticity. J Comp Neurol 357:465-481.

Olavarria J, Van Sluyters RC, Killackey HP (1984) Evidence for the complementary organization of callosal and thalamic connections within rat somatosensory cortex. Brain Res 291:364-368.

Pidoux B, Verley R (1979) Projections on the cortical somatic I barrel subfield from ipsilateral vibrissae in adult rodents. Electroencephalogr Clin Neurophysiol 46:715-726.

Pluto CP, Chiaia NL, Rhoades RW, Lane RD (2005) Reducing contralateral SI activity reveals hindlimb receptive fields in the SI forelimb-stump representation of neonatally amputated rats. J Neurophysiol 94:1727-1732.

Polley DB, Chen-Bee CH, Frostig RD (1999) Two directions of plasticity in the sensory-deprived adult cortex. Neuron 24:623-637.

Rema V, Ebner FF (2003) Lesions of mature barrel field cortex interfere with sensory processing and plasticity in connected areas of the contralateral hemisphere. J Neurosci 23:10378-10387.

Schiffman HR, Lore R, Passafiume J, Neeb R (1970) Role of vibrissae for depth perception in the rat (Rattus norvegicus). Anim Behav 18:290-292.

Schmidt S, Bruehl C, Hagemann G, Witte OW, Redecker C (2006) Impair- ment of functional inhibition in the contralateral cortex following perinatally acquired malformations in rats. Exp Neurol 201:270-274.

Shuler MG, Krupa DJ, Nicolelis MA (2001) Bilateral integration of whisker information in the primary somatosensory cortex of rats. J Neurosci 21:5251-5261.

Shuler MG, Krupa DJ, Nicolelis MA (2002) Integration of bilateral whisker stimuli in rats: role of the whisker barrel cortices. Cereb Cortex 12:86-97.

Smith RL (1973) The ascending fiber projections from the principal sensory trigeminal nucleus in the rat. J Comp Neurol 148:423-445.

Strominger RN, Woolsey TA (1987) Templates for locating the whisker area in fresh flattened mouse and rat cortex. J Neurosci Methods 22:113-118.

Taub E, Uswatte G, Elbert T (2002) New treatments in neurorehabilitation founded on basic research. Nat Rev Neurosci 3:228-236.

Waite PM (1969) Organization of whisker responses in the rat thalamus. J Physiol (Lond) 202:51P-53P.

Watroba L, Buser P, Milleret C (2001) Impairment of binocular vision in the adult cat induces plastic changes in the callosal cortical map. Eur J Neurosci 14:1021-1029.

Welker C, Woolsey TA (1974) Structure of layer IV in the somatosensory neocortex of the rat: description and comparison with the mouse. J Comp Neurol 158:437-453.

Welker E, Hoogland PV, Van der Loos H (1988) Organization of feedback and feedforward projections of the barrel cortex: a PHA-L study in the mouse. Exp Brain Res 73:411-435.

Welker E, Rao SB, Dorfl J, Melzer P, van der Loos H (1992) Plasticity in the barrel cortex of the adult mouse: effects of chronic stimulation upon deoxyglucose uptake in the behaving animal. J Neurosci 12:153-170.

White EL, DeAmicis RA (1977) Afferent and efferent projections of the region in mouse $\mathrm{SmL}$ cortex which contains the posteromedial barrel subfield. J Comp Neurol 175:455-482.

Wong-Riley M (1979) Changes in the visual system of monocularly sutured or enucleated cats demonstrable with cytochrome oxidase histochemistry. Brain Res 171:11-28.

Woolsey TA (2005) Should one hand (paw) really not know what the other is doing? Focus on "reducing contralateral SI activity reveals hindlimb receptive fields in the SI forelimb-stump representation of neonatally amputated rats." J Neurophysiol 94:1666-1667.

Woolsey TA, Van der Loos H (1970) The structural organization of layer IV in the somatosensory region (SI) of mouse cerebral cortex: the description of a cortical field composed of discrete cytoarchitectonic units. Brain Res 17:205-242. 